\title{
Prevotella denticola
}

National Cancer Institute

\section{Source}

National Cancer Institute. Prevotella denticola. NCI Thesaurus. Code C86667.

A species of obligately anaerobic, Gram-negative, rod shaped bacteria assigned to the phylum Bacteroidetes. This species is nonmotile, non-spore forming, produces a tan to buff pigment, fluoresces under UV (365 nm) light, is sucrose, lactose, esculin hydrolysis, beta- $\mathrm{N}$-acetyl-glucosaminidase, and alpha-fucosidase positive, but xylose, arabinose, cellobiose, rhamnose, salicin, indole, beta-glucosidase, and glycine aminopeptidase negative. P. denticola has been isolated from the human gingiva and a variety of clinical specimens. 